\title{
Comparison of Long-Term Angiographic Results of Wide- Necked Intracranial Aneurysms : Endovascular Treatment with Single-Microcatheter Coiling, Double-Microcatheter Coiling, and Stent-Assisted Coiling
}

\author{
Hyun Sik Kim, ${ }^{1}$ Byung Moon Cho, ${ }^{2}$ Chan Jong Yoo, ${ }^{3}$ Dae Han Choi, ${ }^{3}$ Dong Keun Hyun, ${ }^{4}$ Yu Shik Shim, ${ }^{4}$ Joon Ho Song, \\ Jae Keun Oh, ${ }^{1}$ Jun Hyong Ahn, Ji Hee Kim, In Bok Chang' \\ Department of Neurosurgery, Hallym University Sacred Heart Hospital, Anyang, Korea \\ Department of Neurosurgery, ${ }^{2}$ Kangdong Sacred Heart Hospital, Seoul, Korea \\ Department of Neurosurgery, ${ }^{3}$ Gil Medical Center, Gachon University College of Medicine, Incheon, Korea \\ Department of Neurosurgery, ${ }^{4}$ College of Medicine, Inha University, Incheon, Korea
}

Objective : Endovascular treatment of intracranial aneurysms is challenging in case of wide-necked aneurysms because coils are prone to herniate into the parent artery, causing thromboembolic events or vessel occlusion. This study aims to compare long-term angiographic results of wide-necked aneurysms treated by stent-assisted, double-microcatheter, or single-microcatheter groups.

Methods : Between January 2003 and October 2016, 108 aneurysms that were treated with endovascular coil embolization with a neck size wider than $4 \mathrm{~mm}$ and a follow-up period of more than 3 years were selected. We performed coil embolization with singlemicrocatheter, double-microcatheter, and stent-assisted techniques. Angiographic results were evaluated using the Raymond-Roy occlusion classification (RROC). All medical and angiographic records were reviewed retrospectively.

Results : Clinical and angiographic analyses were conducted in 108 wide-necked aneurysms. The immediate post-procedural results revealed RROC class I (complete occlusion) in 66 cases (61.1\%), class II (residual neck) in 36 cases (33.3\%), and class III (residual sac) in six cases (5.6\%). The final follow-up results revealed class I in 48 cases (44.4\%), class II in 49 cases (45.4\%), and class III in 11 cases (10.2\%). Of a total of $45(41.6 \%)$ radiologic recurrences, there were 21 cases (19.4\%) of major recurrence that required additional treatment, and 24 cases (22.2\%) of minor recurrence. The final follow-up angiographic results showed statistically significant differences between the stent-assisted group and the others $(p<0.01)$.

Conclusion : Long-term follow-up angiography demonstrated that the stent-assisted technique had a better complete occlusion rate than the other two techniques.

Key Words : Intracranial aneurysm, wide necked · Endovascular procedures · Embolization · Stent-assisted coiling.

- Received : January 13, 2021 •Revised : March 30, 2021 •Accepted : May 21, 2021

- Address for reprints : In Bok Chang

Department of Neurosurgery, Hallym University Sacred Heart Hospital, 22 Gwanpyeong-ro, 170beon-gil, Dongan-gu, Anyang 14068, Korea

Tel : +82-31-380-3771, Fax : +82-31-380-1900, E-mail : nscib71@hanmail.net, ORCID : https://orcid.org/0000-0001-8003-3264

This is an Open Access article distributed under the terms of the Creative Commons Attribution Non-Commercial License (http://creativecommons.org/licenses/by-nc/4.0) which permits unrestricted non-commercial use, distribution, and reproduction in any medium, provided the original work is properly cited. 


\section{INTRODUCTION}

Since the US Food and Drug Administration approved the use of detachable coils for the endovascular occlusion of intracranial aneurysms in 1995, endovascular treatment of intracranial aneurysms using a platinum coil has become widespread. Recently, remarkable developments in endovascular devices and techniques have extended the range of treatments for complex intracranial aneurysms, resulting in better angiographic and clinical outcomes. In spite of these developments, complete obliteration of the aneurysm using a single microcatheter remains challenging in cases of large or wide-necked aneurysms ( $\geq 4 \mathrm{~mm})$.

The possibility of herniation of the deployed coils into the parent vessel in wide-necked aneurysms is relatively high, and herniation precludes total obliteration of the aneurysms ${ }^{14)}$. Incomplete obliteration is prone to coil compaction and recurrence, leading to additional treatment. To complement imperfect occlusion, double-microcatheter coiling (DMC), stentassisted coiling (SAC), and balloon-assisted coiling (BAC) are used in these cases to prevent herniation of coils or coil compaction $^{11,19)}$. Some studies reported a complete occlusion rate of $71 \%$ in $\mathrm{BAC}^{26)}$ at 6 months follow-up, and $57-60 \%$ in $\mathrm{SAC}^{10,16)}$ at 6 and 12 months follow-up. Another study compared immediate post-procedural angiographic results of 207 patients for SAC, BAC, and DMC and found no differences among the three groups (complete occlusion rate of $63.8 \%$, $62.9 \%$, and $46.7 \%$, respectively) ${ }^{4)}$. They also found no differences in recurrence rates among three groups $(7.1 \%, 8.6 \%$, and $11.1 \%$, respectively).

Although many studies have reported various results regarding the treatment of wide-necked aneurysms, their follow-up evaluation periods ranged from 6 months to 1 year, which is not long enough to identify changes on angiography. Therefore, we decided to investigate cases with long-term follow-up of at least 3 years, and aimed to compare the radiographic results of coil embolization of wide-necked aneurysms according to treatment techniques.

\section{MATERIALS AND METHODS}

All procedures performed in studies involving human participants were in accordance with the ethical standards of the
Institutional and/or National Research Committee of Hallym University Sacred Heart Hospital (Hallym 2019-10-026-001) and with the 1964 Helsinki declaration and its later amendments or comparable ethical standards. The need for informed consent was waived due to the retrospective nature of this study.

\section{Patient characteristics}

We chose patients, with wide-necked aneurysm and longterm follow-up periods after initial coil embolization, from four hospitals regardless of age and sex between January 2003 and October 2016. As our previous report in 2015 ${ }^{27)}$, aneurysms were considered wide-necked if the neck was larger than $4 \mathrm{~mm}$ or the dome-to-neck ratio was less than 2 , and the

Table 1. Characteristics of 108 aneurysms

\begin{tabular}{|c|c|}
\hline Characteristic & Value \\
\hline \multicolumn{2}{|l|}{ Sex } \\
\hline Male & $26(24.1)$ \\
\hline Female & $82(75.9)$ \\
\hline Age (years) & $55.64 \pm 10.04(27-87)$ \\
\hline Follow up period (months) & $58.36 \pm 25.08(36-131)$ \\
\hline Ruptured & $58(53.7)$ \\
\hline \multicolumn{2}{|l|}{ Hunt-Hess grade } \\
\hline Grade I-II & $28(48.3)$ \\
\hline Grade III-V & $30(51.7)$ \\
\hline \multicolumn{2}{|l|}{ Fisher grade } \\
\hline Grade I-II & $24(41.4)$ \\
\hline Grade III-V & $34(58.6)$ \\
\hline \multicolumn{2}{|l|}{ Clinical outcome, mRS } \\
\hline $0-2$ & $52(89.7)$ \\
\hline $3-5$ & $6(10.3)$ \\
\hline Unruptured & $50(46.3)$ \\
\hline \multicolumn{2}{|l|}{ Technique } \\
\hline Single-microcatheter & $39(36.1)$ \\
\hline Double-microcatheter & $34(31.5)$ \\
\hline Stent-assisted & $35(32.4)$ \\
\hline \multicolumn{2}{|l|}{ Aneurysm size } \\
\hline Small, $<10 \mathrm{~mm}$ & $84(77.8)$ \\
\hline Large, 10-25 mm & $24(22.2)$ \\
\hline Giant, $>25$ mm & $0(0.0)$ \\
\hline
\end{tabular}

Values are presented as mean \pm standard deviation (range) or number (\%). mRS : modified Rankin Scale 
follow-up period was considered long-term if it was longer than 3 years after the initial embolization. Aneurysms less than $4 \mathrm{~mm}$ in neck size and patients with a follow-up period of less than 3 years were excluded. There were 2480 cases of endovascular coil embolization in total, between January 2003 and October 2016. Of these, 521 were wide-necked aneurysm cases and 108 cases had a more than 3 -year follow-up. Of these 108 patients, $26(24.1 \%)$ were men, and 82 (75.9\%) were women. Their mean age \pm standard deviation (SD) was $55.64 \pm 10.05$ years, ranging from 27 to 87 years. Fifty-eight cases (53.7\%) were ruptured aneurysms, and 50 cases (46.3\%) were unruptured aneurysms. Single-microcatheter coiling (SMC) was performed in 39 cases (36.1\%), DMC was performed in 34 (31.5\%), and SAC was performed in 35 cases (32.4\%). The reviewed characteristics included sex, age, follow-up period, aneurysm size, aneurysm nature (ruptured or unruptured), Hunt-Hess grade, Fisher grade, and clinical outcome. The characteristics of the 108 aneurysms are described in Table 1.

\section{Procedures}

A biplane digital subtraction angiographic device (Philips Allura Xper; Philips, Amsterdam, The Netherlands) has been used for cerebral angiography and coil embolization in our hospital since 2007. Prior to 2007, a monoplane angiographic unit was used. All the patients undergoing coil embolization were under general anesthesia.

Before about 2010, we first performed coil embolization with a single-microcatheter, and if the first frame coil steadily formed a stable basket in the aneurysmal sac, we perform SMC (Fig. 1). In the case of unstable basket formation with the first frame coil, we selected the aneurysm with an additional microcatheter (Fig. 2). If the basket was not steadily main-
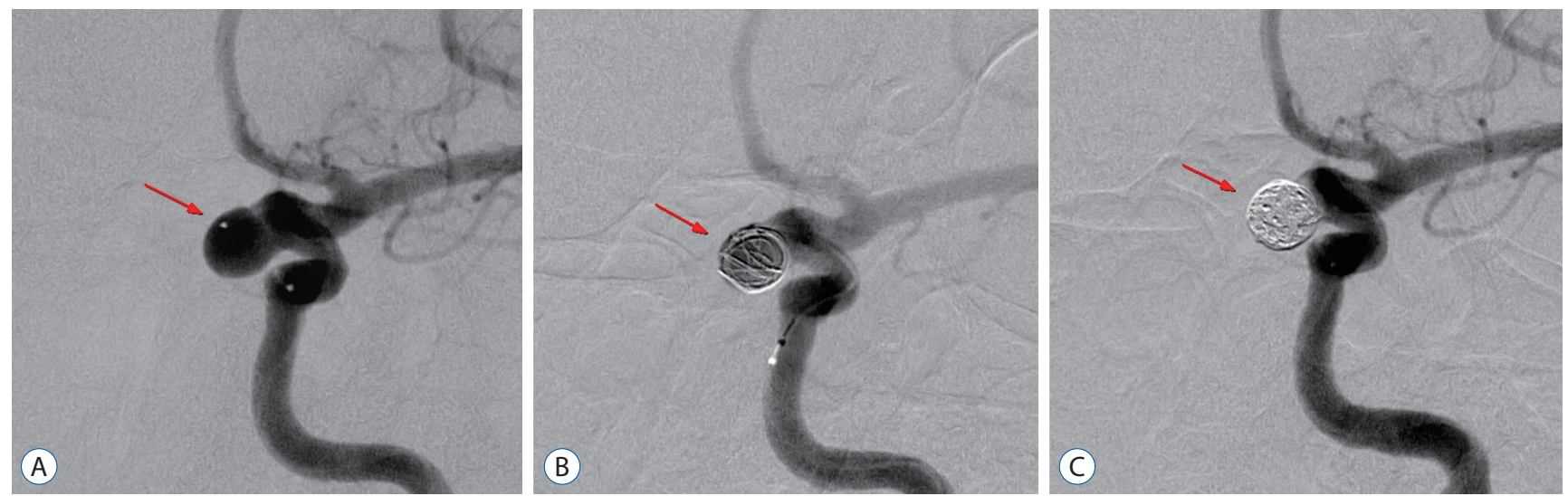

Fig. 1. Single-microcatheter technique of coil embolization. A : A left paraclinoid segment aneurysm was selected with a microcatheter (arrow). B : A frame coil formed stable bascket in the aneurysmal sac (arrow). C : Coil embolization with single-microcatheter was done successfully (arrow).
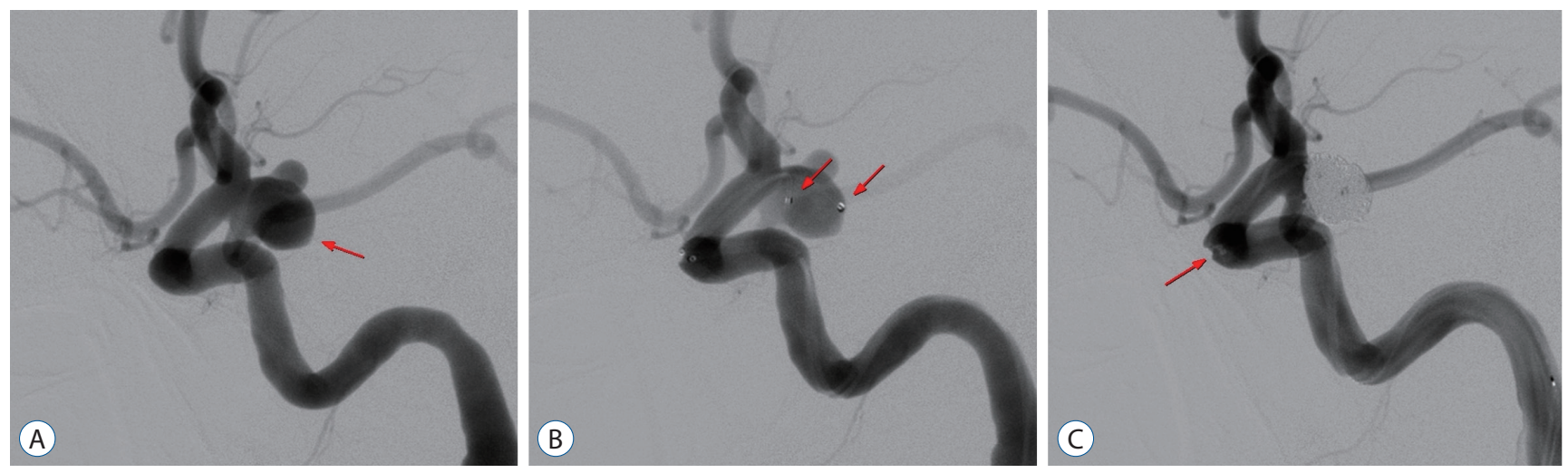

Fig. 2. Double-microcatheter technique of coil embolization. A : An aneurysm of right posterior communicating artery is shown (arrow). B : The aneurysm is selected with two microcatheters and distal tips of microcatheters are marked with arrows. C : Coil embolization was done and proximal markers of two microcatheters are shown (arrow). 
tained even when a double-microcatheter was used, SAC was chosen in the next step (Fig. 3). After we've gained experience and become accustomed to using the stent, after about 2010, administration of dual antiplatelet agents and SAC was performed if SAC was considered appropriate, especially in case of dome-to-neck ration $<1.5$. Ten series of microcatheters, including Prowler-10 (Cordis, Miami, FL, USA) and Excelsior SL-10 (Boston Scientific, Fremont, CA, USA) were used. Of 108 aneurysms, SMC was performed in 39 cases and DMC was performed in 34 cases.

Enterprise (Codman, Raynham, MA, USA), Solitaire (EV3, Irvine, CA, USA), and Neuroform (Boston Scientific) stents were used in this study. When the use of a stent was anticipated, 1 tablet of $100 \mathrm{mg}$ of aspirin and 1 tablet of $75 \mathrm{mg}$ of clopidogrel were administered, for 5 days prior to the procedure, to the elective patients. Patients with ruptured aneurysms scheduled to undergo SAC were administered $300 \mathrm{mg}$ of aspirin and $300 \mathrm{mg}$ of clopidogrel through a Levin tube after general anesthesia. We performed SAC in 35 cases. Systemic heparinization was performed for all patients during the procedure. Patients were administered daily doses of $100 \mathrm{mg}$ aspirin and $75 \mathrm{mg}$ clopidogrel for at least 3 months after embolization. Immediate post-coil embolization results were evaluated using the Raymond-Roy occlusion classification (RROC) ${ }^{24)}$.

\section{Angiographic results and follow-up}

The first follow-up angiography after coil embolization was scheduled at 6 months or 12 months, and the second followup evaluation was scheduled at 1-2 years after the first followup angiography. The RROC was used on follow-up angiographic results, similar to the immediate post-procedural evaluation; class I represents complete obliteration of both the aneurysmal neck and sac; class II represents partial obliteration of the aneurysm with a residual neck; and class III denotes incomplete obliteration of the aneurysm with a residual sac. Angiographic recurrence was defined as new contrast fill-
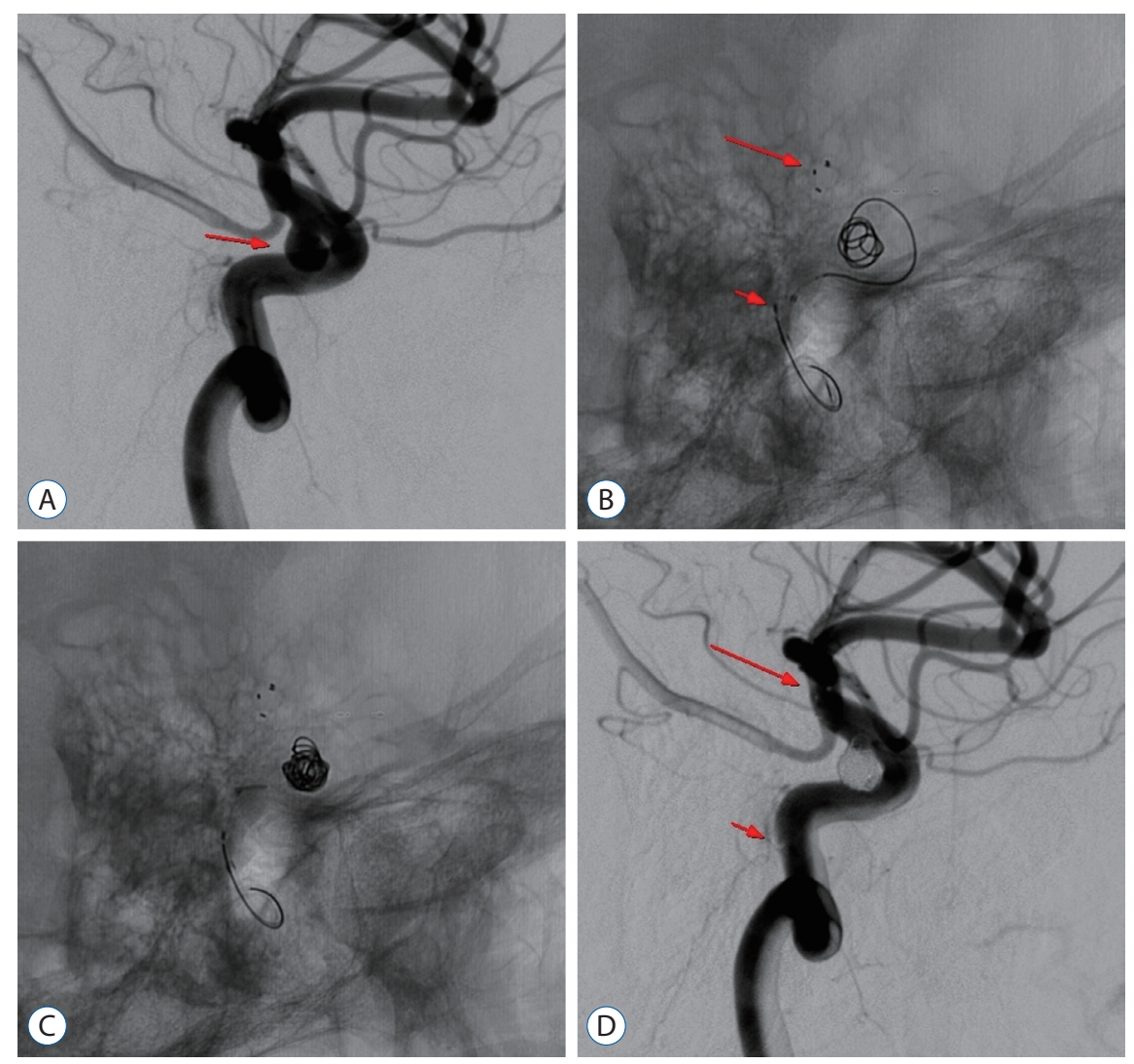

Fig. 3. Stent-assisted coil embolization of ophthalmic segment of left internal carotid artery. A : An ophthalmic segment aneurysm of left internal carotid artery is shown (arrow). B : A first frame coil is partially deployed and distal marker (long arrow) and proximal marker (short arrow) of deployed stent is shown. C : Additional coils were deployed in the aneurysm. D : Coil embolization is done and distal marker (long arrow) and proximal marker (short arrow) of deployed stent is shown. 
ing, or any enlarged contrast filling area of the aneurysmal neck or sac in follow-up angiographies ${ }^{27}$. To assess the durability and stability of the coil embolization, we subdivided recurrence into minor and major groups. A minor recurrence was defined as a new contrast filling of the aneurysmal neck, which was previously completely obliterated (Fig. 4). A major recurrence was defined as a new contrast filling of the aneurysmal sac, which was previously completely occluded, or an
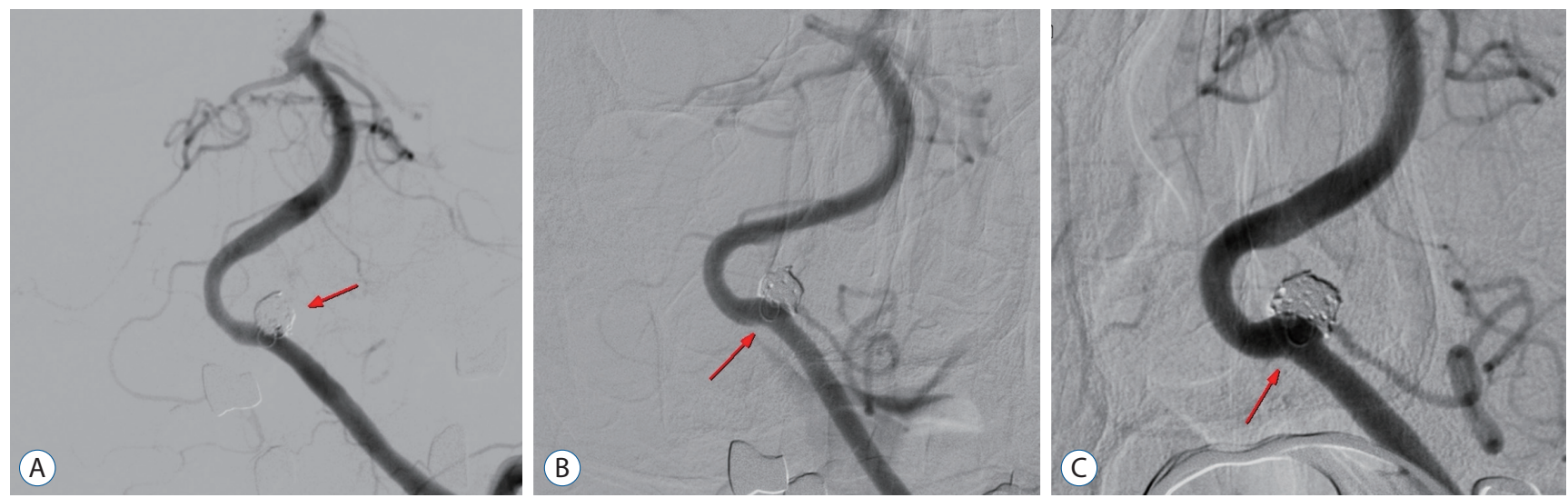

Fig. 4. Cerebral angiography of a 65-year-old woman showing minor recurrence. A : An immediate angiogram after coil embolization of left vertebral artery aneurysm (arrow). B : A 10 months follow-up angiography shows mild coil compaction (arrow). C : A 42 months follow-up angiography shows contrast filling of the aneurysmal neck but no more severe compaction (arrow).
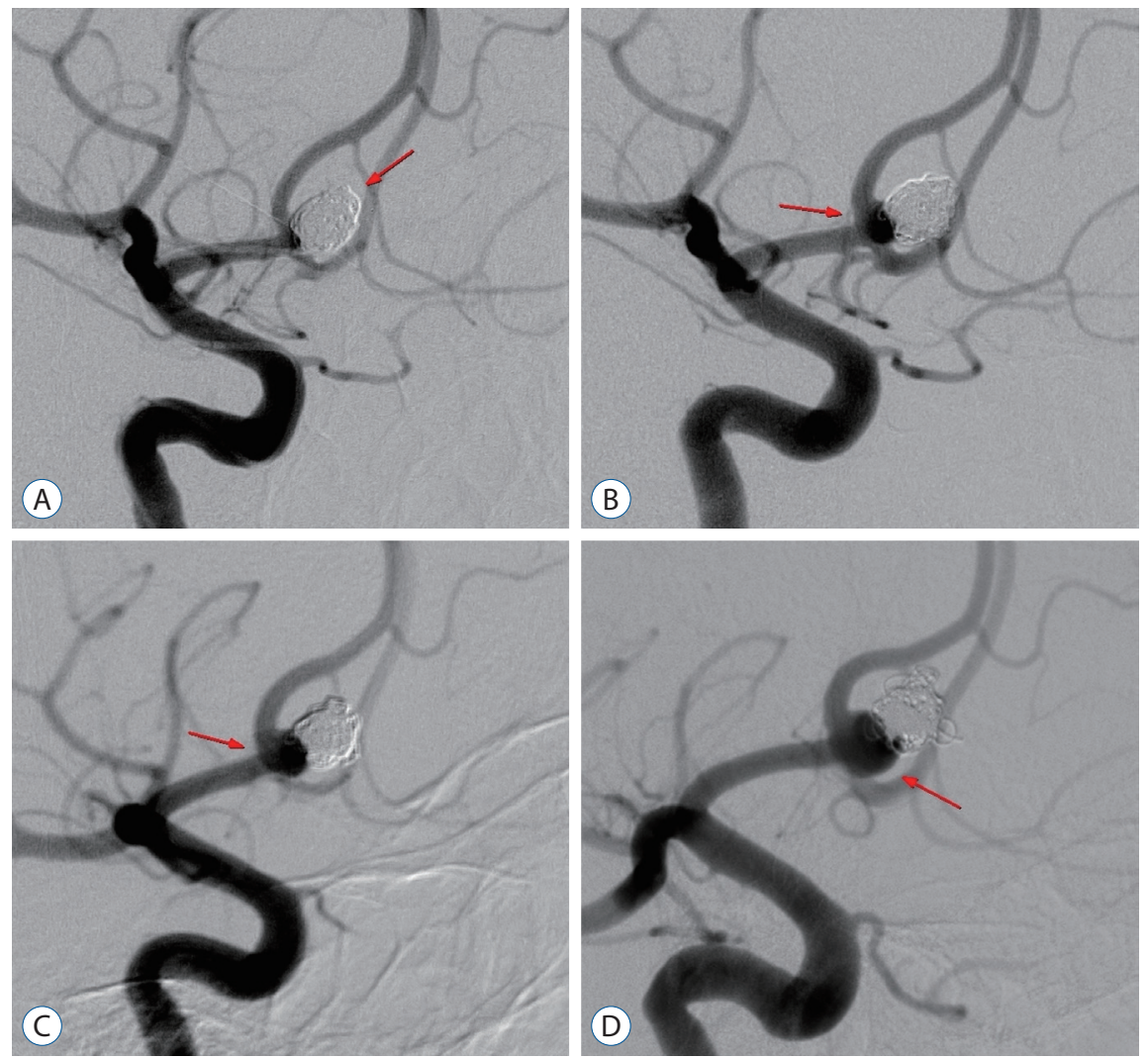

Fig. 5. Cerebral angiography of a 54-year-old man showing major recurrence. A : An immediate angiogram after coil embolization of anterior communicating artery aneurysm (arrow). B : A 10 months follow-up angiography shows contrast filling of the aneurysmal neck (arrow). C : A 24 months follow-up angiography shows enlarged contrast filling area (arrow) and coil compaction. D : A 10 years follow-up angiography shows severe coil compaction and major recurrence of the aneurysm (arrow). 
increase in the filling of the sac (Fig. 5) ${ }^{27)}$. The mean follow-up period was $58.36 \pm 25.08$ months, ranging from 36 to 131 months.

\section{Clinical outcomes and procedure-related compli- cations}

Clinical outcomes were assessed using the modified Rankin Scale $(\mathrm{mRS})^{7)}$ at the point of discharge. Procedure-related complications were documented, including thromboembolic events, intraoperative rupture, branching artery occlusion, and coil herniation.

\section{Statistical analysis}

Statistical Package for the Social Sciences software version 26 (SPSS Inc., Chicago, IL, USA) was used for statistical analysis. A Cox proportional hazard model was used to identify the risk factors that may be associated with recurrence, including immediate angiographic results, age, sex, aneurysm size, and location. Cross-tabulation was performed to compare the recurrence rate, immediate radiologic results, and follow-up radiologic results among the three groups. A $p$-value less than 0.05 was considered statistically significant.

\section{RESULTS}

A total of 108 wide-necked aneurysms were evaluated. The mean neck size was $5.22 \pm 1.22 \mathrm{~mm}$ and mean aneurysm size was $7.99 \pm 3.35 \mathrm{~mm}$. Fifty (46.3\%) were unruptured, and 58 (53.7\%) were ruptured. The ruptured aneurysms were graded according the Hunt-Hess ${ }^{13)}$ and Fisher scales ${ }^{9}$ at the point of hospital admission. For the Hunt-Hess scale, seven cases were grade I, 21 cases were grade II, 22 cases were grade III, eight cases were grade IV, and 0 cases were grade V. For the Fisher scale, 0 cases were grade I, 24 cases were grade II, 25 cases were grade III, and nine cases were grade IV (Table 1).

SMC was performed in 39 cases (36.1\%), DMC in 34 cases (31.5\%), and SAC in 35 cases (32.4\%). The most frequent location of aneurysm was the anterior communicating artery $(\mathrm{n}=25,24.3 \%)$, followed by the posterior communicating artery $(n=20,19.4 \%)$, paraclinoid segment $(n=12,11.7 \%)$, ophthalmic segment ( $\mathrm{n}=11,10.7 \%)$, middle cerebral artery bifurcation $(n=10,9.7 \%)$, basilar artery $(n=10,9.7 \%)$, and others $(n=15,14.6 \%)$.

\section{Immediate post-procedural angiographic out- comes}

Of the 108 aneurysms, the initial angiographic results showed a RROC of class I in 66 cases (61.1\%), class II in 36 cases (33.3\%), and class III in six cases (5.6\%) (Table 2). Immediate post procedural angiographic results of SMC showed class I in 21 cases (53.9\%), class II in 16 cases (41.0\%), and class III in two cases (5.1\%). In the 34 aneurysms treated with DMC, class I was seen in 20 cases (58.8\%), class II in 12 cases (35.3\%), and class III in two cases (5.9\%). For SAC, class I was seen in 25 cases $(71.5 \%)$, class II in eight cases $(22.8 \%)$, and

Table 2. Endovascular treatment techniques and angiographic results

\begin{tabular}{|c|c|c|}
\hline Characteristic & $\begin{array}{c}\text { Value } \\
\text { (108 aneurysms) }\end{array}$ & $p$-value \\
\hline $\begin{array}{l}\text { Immediate post procedural } \\
\text { angiographic results }\end{array}$ & & 0.578 \\
\hline Single-microcatheter & 39 & \\
\hline Raymond I & $21(53.9)$ & \\
\hline Raymond II & $16(41.0)$ & \\
\hline Raymond III & $2(5.1)$ & \\
\hline Double-microcatheter & 34 & \\
\hline Raymond I & $20(58.8)$ & \\
\hline Raymond II & $12(35.3)$ & \\
\hline Raymond III & $2(5.9)$ & \\
\hline Stent-assisted & 35 & \\
\hline Raymond I & $25(71.5)$ & \\
\hline Raymond II & $8(22.8)$ & \\
\hline Raymond III & $2(5.7)$ & \\
\hline The last follow up angiographic results & & 0.001 \\
\hline Single-microcatheter & 39 & \\
\hline Raymond I & $14(35.9)$ & \\
\hline Raymond II & $19(48.7)$ & \\
\hline Raymond III & $6(15.4)$ & \\
\hline Double-microcatheter & 34 & \\
\hline Raymond I & $10(29.4)$ & \\
\hline Raymond II & $19(55.9)$ & \\
\hline Raymond III & $5(14.7)$ & \\
\hline Stent-assisted & 35 & \\
\hline Raymond I & $24(68.6)$ & \\
\hline Raymond II & $11(31.4)$ & \\
\hline Raymond III & $0(0.0)$ & \\
\hline
\end{tabular}

Values are presented as number (\%) 
class III in two cases (5.7\%). Cross-tabulation was performed to compare the immediate radiological results, and there were no statistically significant differences among the three groups in terms of $\operatorname{RROC}(p=0.578)$.

\section{Final follow-up angiographic outcomes}

All 108 aneurysms had a follow-up period of at least 36 months, and the mean follow-up term was 58.36 \pm 25.08 months, ranging from 36 months to 131 months. The final angiographic results of SMC showed RROC class I in 14 cases (35.9\%), class II in 19 cases (48.7\%), and class III in six cases (15.4\%) (Table 2). In the 34 aneurysms treated with the DMC, class I was seen in 10 cases (29.4\%), class II in 19 cases (55.9\%), and class III in five cases (14.7\%). For SAC, class I was seen in 24 cases $(68.6 \%)$, class II in 11 cases (31.4\%), and there were no class III cases. Cross-tabulation was performed to compare the final follow-up radiological results, and there were statistically significant differences among the three groups in terms of $\operatorname{RROC}(p<0.01)$.

Radiological recurrence was found in 45 patients (41.7\%). Recurrence was defined based on the degeneration of the RROC. There were 35.5\% (16/45) recurrent cases among aneurysms treated using SMC, 46.7\% (21/45) recurrent cases of aneurysms treated using DMC, and 17.8\% (8/45) recurrent cases of aneurysms treated using SAC. There was a statistically significant difference according to the treatment techniques $(p<0.01)$. There were 27 cases in which the change was from RROC class I to II, seven cases from class I to III, and 11 cases from class II to III.

Recurrent aneurysms were retreated with additional coil embolization or surgical aneurysmal neck clipping if a $>30 \%$ increase in coil compaction area was found (major recurrence). Of the 45 recurrent aneurysms, 19 cases had additional coil embolization, one case had surgical neck clipping, and 25 cases with minor recurrence were observed (Table 3). Initial angiographic results $(p=0.015)$ were significantly associated with major recurrence using Cox's proportional hazard model analysis (Table 4).

At the point of discharge, we determined the mRS score. There were nine patients with a score of 0,40 patients with a score of 1 , three patients with a score of 2 , two patients with a score of 3 , three patients with a score of 4 , one patient with a score of 5 , and there were no patients with a score of 6 because we evaluated more than 3 years of follow-up data.

Table 3. Minor and major angiographic recurrence according to initial angiographic results

\begin{tabular}{lcc}
\hline \multirow{2}{*}{ Initial angiographic result } & \multicolumn{2}{c}{ Recurrence (45/108; 41.7\%) } \\
\cline { 2 - 3 } & Minor recurrence & Major recurrence \\
\hline Complete occlusion $(n=66)$ & $25(37.9)$ & $8(12.1)$ \\
Residual neck $(n=36)$ & $0(0.0)$ & $11(30.6)$ \\
Residual sac $(n=6)$ & $0(0.0)$ & $1(16.7)$ \\
Total ( $n=108)$ & $25(23.1)$ & $20(18.5)$ \\
First recurrent time (months) & $15.76 \pm 5.83(1-71)$ & $22.65 \pm 8.54(4-73)$ \\
\hline
\end{tabular}

Values are presented as mean \pm standard deviation (range) or number (\%)

Table 4. Variables associated with major recurrence

\begin{tabular}{|c|c|c|c|c|}
\hline \multirow{2}{*}{ Variable } & \multicolumn{4}{|c|}{ Cox's proportional Hazard model } \\
\hline & Parameter estimate & SE & OR $(95 \% \mathrm{Cl})$ & $p$-value \\
\hline Rupture status (ruptured or unruptured) & 0.324 & 0.534 & $1.382(0.485-3.939)$ & 0.545 \\
\hline Treatment technique & 1.450 & 0.747 & $4.265(0.987-18.429)$ & 0.052 \\
\hline Aneurysmal sac size (small or large) & 0.509 & 0.504 & $1.664(0.619-4.472)$ & 0.313 \\
\hline Initial angiographic results (complete or incomplete) & 0.851 & 0.349 & $2.341(1.181-4.641)$ & 0.015 \\
\hline
\end{tabular}

Adjusted by age, sex, and Hunt-Hess grade. SE : standard error, OR : odds ratio, Cl : confidence interval 


\section{DISCUSSION}

\section{Comparison of techniques in wide-necked aneu- rysms}

Technological developments in the neuroendovascular field has expanded the indication for endovascular treatment of aneurysms, which were previously deemed uncoilable. However, in the case of wide-necked aneurysms, providing suitable coil density is difficult without any assistance device or technique. Fernandez Zubillaga et al. ${ }^{8)}$ reported complete obliteration in only $15 \%$ of broad-necked aneurysms, as compared with $85 \%$ of aneurysms with a narrow neck. Raymond and Roy reported that they treated 75 patients with an endovascular approach and 12 recurrences were observed, 6 to 36 months after treatment ${ }^{23)}$. The recurrences were observed mainly in aneurysms with a wide neck (eight patients), as compared to aneurysms with a small neck (four patients).

\section{Stent-assisted technique}

SAC provides neck support and serves as a barrier precluding coil herniation into the parent artery (Fig. 3) ${ }^{29)}$. Some studies reported that the complete occlusion rate in SAC of intracranial aneurysm was seen in $57-61 \%$ of cases ${ }^{10,16,25)}$. However, SAC requires dual antiplatelet therapy to prevent in-stent thrombosis, which increases hemorrhagic complications related to extraventricular drainage catheter placement, or other possible surgical procedures for additional management ${ }^{17,21)}$. Overall morbidity ranges from $1.5 \%$ to $3 \%$ with $\mathrm{SAC}^{3,15)}$. Several studies compared SAC and BAC in treating wide-necked aneurysm. Cai et al. ${ }^{2)}$ compared 65 cases treated with SAC and 32 with BAC in the treatment of ruptured wide-necked aneurysms and concluded that occlusion rates, periprocedural complications, and favorable outcomes are not statistically different between the two techniques. Consoli et al. ${ }^{5)}$ compared 122 cases treated with SAC and 164 with BAC in the treatment of ruptured wide-necked aneurysms and reported that the complete occlusion rate at the end of the procedure was higher with SAC than with BAC (86.8\% vs. 78\%), and the same results were observed after 6 months $(92.1 \%$ vs. $77.6 \%$; $p=0.05)$.

\section{Double-microcatheter technique}

One alternative method to BAC or SAC is to use a dual microcatheter. In 1998, Baxter et al. ${ }^{1)}$ first reported the use of
DMC. Two microcatheters are positioned in the aneurysmal sac simultaneously in this technique, which allows coils to remain in place, interweaving each other to reduce the chance of coil herniation (Fig. 4). There is no need to use additional devices to deliver a balloon or stent in this technique. Especially in cases of subarachnoid hemorrhages, DMC has the obvious benefit of no need for routine antiplatelet drugs, which increases the risk of bleeding. Durst et al. ${ }^{6)}$ performed coil embolization of 100 wide-necked aneurysms using a dual microcatheter. They reported a 91\% technical success rate; $1 \%$ and $2 \%$ treatment-related morbidity and mortality rates, respectively; $75 \%$ total obliteration rate (57 cases of initial obliteration and 18 cases of progressive occlusion on follow-up studies); and 18\% retreatment rates. We reported 22 aneurysms treated with multiple microcatheter systems in our previous study; nine cases (40.9\%) showed total obliteration and six cases $(27 \%)$ had recurred at the final follow-up evaluation ${ }^{27)}$.

Recent studies on coiling techniques have demonstrated the differences in angiographic results among several groups. One study compared the differences among SAC, DMC, and BAC of wide-necked aneurysms ${ }^{4}$. They selected 207 wide-necked aneurysms and evaluated initial occlusion rates, recanalization rates, and procedural complications for a mean follow-up period of 16.2 months. They concluded that there were no statistically significant differences in the recurrence rate, periprocedural complications, and occlusion rates among the three groups. Starke et al. ${ }^{28)}$ compared DMC and SAC in treating unruptured wide-necked intracranial aneurysms. They evaluated 100 patients treated with DMC and 160 patients with SAC, and their mean follow-up period was 27.0 \pm 18.9 months. Obliteration rates were not significantly different in those treated with SAC (63.7\%) versus double-microcatheter technique (64.2\%). The overall rate of major complications that resulted in permanent morbidity in the DMC group was $1.7 \%$ and $8.3 \%$ in the SAC group, and these rates were not statistically different. The mean follow-up periods of both studies were less than 3 years.

In our study, immediate postprocedural angiographic results using the RROC showed no statistically significant differences among the three groups $(p=0.57)$. However, the final follow-up angiographic results demonstrated that there were statistically significant differences among the three groups ( $p=0.001$ ). When we divided the three groups into two groups, the stent-assisted group versus the non-stent group, there was 
a significant difference in the final follow-up angiographic results between these two groups ( $p=0.003$ ). We believe that two main factors caused these results. First, we could insert more coils in SAC cases because the stent acts as a barrier to prevent coils from protruding into the parent artery. Second, the stent could act as a scaffold that promotes neointima formation and, at the same time, interrupts normal blood flow creating favorable for blood clot formation. In total, there were 11 cases of spontaneous thrombosis, seven in the SAC group and four in the non-stent group. We also compared the SMC and DMC groups, and there were no statistically significant differences between these two groups $(p=0.276)$. This means that the stent-assisted technique is a better method in terms of obliteration.

\section{Risk factors for recurrence}

Recurrence is defined as contrast filling of the aneurysmal neck or sac after treatment ${ }^{27)}$. The rate of complete occlusion coil embolization is between $27-79 \%$ (median, 55\%). Incomplete obliterated aneurysms have a high recurrence rate of $7-39 \%{ }^{18)}$. In 2003, Raymond and Roy reported long-term angiographic recurrences after endovascular treatment of aneurysms (mean \pm SD follow-up was $31.32 \pm 24.96$ months) and important predictors of a recurrence included aneurysm size $>10$ $\mathrm{mm}$, treatment during the acute phase of rupture, incomplete initial occlusions, and duration of follow-up ${ }^{22)}$. Another study evaluated 83 patients who experienced recurrence after endovascular treatment ${ }^{12)}$. They concluded that aneurysm size $>10$ $\mathrm{mm}$, volume embolization ratio less than 20\%, and widenecked aneurysms are risk factors for postoperative recurrence of an aneurysm. Another study evaluated 818 patients harboring 916 aneurysms treated with coil embolization, and the overall recurrence rate was 20.9\% (angiographic followups were obtained in 480 of 916 aneurysms, and recurrence was observed in 102 of 489 aneurysms, with a mean follow-up of 11 months) ${ }^{20)}$. Recanalization occurred more frequently in the wide-necked group and in large or giant aneurysms. In our previous study in 2015, we evaluated 53 wide-necked aneurysms treated with coil embolization, and only the suboptimal initial angiographic result was a significant predictor of recurrence $(p=0.03)^{27)}$.

In this study, there were $45(41.7 \%)$ recurrent radiologic cases. Sixteen recurrences were found in the SMC group, 21 in the DMC group, and eight in the SAC group. There were sta- tistically significant differences among the three groups $(p=0.002)$. When we divided the three groups into two groups of stent-assisted versus non-stent, there was a $22.8 \%(8 / 35)$ recurrence in the stent-assisted group and a 50.7\% (37/73) recurrence in the non-stent using group. This result was also statistically significant $(p=0.01)$. Taken together, SAC has the highest durability in that there is less recurrence using this method.

We investigated the risk factors related to recurrence (Table 4). Cox's proportional hazard model was evaluated, and only initial incomplete angiographic results met statistical significance (odds ratio, 2.341; 95\% confidence interval, 1.181-4.641; $p=0.015)$. There were statistically significant differences among the SMC, DMC, and SAC groups in the angiographic results when we used cross-tabulation. However, multivariate analysis showed that treatment technique was not a risk factor associated with major recurrence $(p=0.052)$, although SAC showed less recurrence than non-stent use groups. This is because multiple factors were adjusted for, and these affect each other in multivariate analysis. Although treatment technique was not a risk factor in this study, the stent-using technique would be likely show statistically meaningful results associated with recurrence in a future large-scale study.

\section{Recurrence time and spontaneous thrombosis}

We also evaluated the recurrence time after embolization. There was $48.9 \%$ (22/45) recurrence within 1 year after embolization, 20\% (9/45) recurrence between 1 and 2 years, $8.9 \%$ (4/45) recurrence between 2 to 3 years, and 22.2\% (10/45) recurrence over 3 years. Most changes occurred within 1 year (48.9\%) from the initial procedure, and many changes occurred after 3 years (22.2\%). Minor recurrence occurred at 15.76 months after first coiling (range, 1-71 months) and major recurrence occurred at 22.65 months (range, 4-73 months) (Table 3). These results show that the aneurysm embolization state should be followed-up for at least 3 years to detect any changes, including recanalization, which need retreatment. Therefore, we suggest that radiologic evaluation should be conducted every year for at least 3 years. In the many studies mentioned above that reported on different embolization techniques, the results might have changed if cases had been followed-up for more than 3 years.

Spontaneous thrombosis was also observed, as opposed to recurrence. Spontaneous thrombosis is defined based on the 
improvement of the RROC. There were 11 cases (10.2\%) of spontaneous thrombosis in this study. Seven cases improved within 1 year, three cases between 1 and 2 years, and one case over 3 years. Most cases of spontaneous thrombosis occurred within 2 years after embolization. Considering both recurrence and spontaneous thrombosis time, we can conclude that one should follow-up the results for at least 3 years after the procedure to detect any changes.

\section{Limitations}

This study included wide-necked aneurysm $>4 \mathrm{~mm}$ and long-term follow-up results over 3 years. Therefore, there were few severely ill patients with mRS scores ranging from 3 to 5 , and patients with scores of 6 were excluded because there were no follow-up data of more than 3 years for deceased patients. Almost all the results in this study are based on relatively healthy patients. Therefore, we could not calculate the exact mortality and morbidity.

We did not divide the patient group into rupture and unrupture when comparing SMC, DMC, and SAC. There may be differences between the rupture group and the unruptured group, but the focus of this paper is on the change of angiographic results and recurrence of wide-necked aneurysms, so the two groups are compared without distinguishing. If the two groups were analyzed separately, there is a possibility that the results are different from now.

We used the RROC to describe the embolization state of aneurysms in this study, which could be scored differently depending on the doctor. Angiographic images were crosschecked by three different interventional neuroradiologists to minimise the differences in opinion between examiners, but there is still room for controversy regarding scoring.

We evaluated long-term follow-up results for more than 3 years, and this is a longer follow-up period than that of other published reports. However, no one can anticipate what changes will occur after a longer period. Therefore, longer follow-up results of more than 3 years are needed. Recently, many studies have used flow-diverter devices, but this study did not. It would be better to use the latest devices, such as flow-diverter stents, in future studies.

\section{CONCLUSION}

Initial post-procedural angiographic results demonstrated no differences among the SMC, DMC, and SAC groups, but long-term follow-up angiographic results were statistically significantly different among the three groups. The SAC group showed the highest complete occlusion rate and lowest recurrence rate. Initial angiographic result was the only risk factor associated with major recurrence. We suggest that follow-up evaluation should be performed at least 3 years after endovascular treatment of an aneurysm.

\section{CONFLICTS OF INTEREST}

No potential conflict of interest relevant to this article was reported.

\section{INFORMED CONSENT}

This type of study does not require informed consent.

\section{AUTHOR CONTRIBUTIONS}

\author{
Conceptualization : IBC, HSK \\ Data curation : IBC, HSK, BMC, CJY, DHC, DKH, YSS \\ Formal analysis : IBC, HSK \\ Methodology : HSK, JHS, JKO, JHA, JHK \\ Project administration : HSK, IBC \\ Visualization : HSK \\ Writing - original draft : HSK \\ Writing - review \& editing : IBC
}

\section{ORCID}

$\begin{array}{ll}\text { Hyun Sik Kim } & \text { https://orcid.org/0000-0003-0639-4162 } \\ \text { Byung Moon Cho } & \text { https://orcid.org/0000-0001-9906-8125 } \\ \text { Chan Jong Yoo } & \text { https://orcid.org/0000-0002-2680-7692 } \\ \text { Dae Han Choi } & \text { https://orcid.org/0000-0001-5281-2770 } \\ \text { Dong Keun Hyun } & \text { https://orcid.org/0000-0002-9318-5985 } \\ \text { Yu Shik Shim } & \text { https://orcid.org/0000-0002-3311-8764 }\end{array}$ 
Joon Ho Song

https://orcid.org/0000-0001-6772-1118

Jae Keun Oh

Jun Hyong Ahn

Ji Hee Kim

In Bok Chang https://orcid.org/0000-0002-8529-6757

https://orcid.org/0000-0001-8003-3264 https://orcid.org/0000-0001-6937-8093

\section{References}

1. Baxter BW, Rosso D, Lownie SP : Double microcatheter technique for detachable coil treatment of large, wide-necked intracranial aneurysms.

AJNR Am J Neuroradiol 19 : 1176-1178, 1998

2. Cai K, Zhang Y, Shen L, Ni Y, Ji Q : Comparison of stent-assisted coiling and balloon-assisted coiling in the treatment of ruptured wide-necked intracranial aneurysms in the acute period. World Neurosurg 96 : 316-321, 2016

3. Chalouhi N, Starke RM, Koltz MT, Jabbour PM, Tjoumakaris SI, Dumont AS, et al. : Stent-assisted coiling versus balloon remodeling of wide-neck aneurysms: comparison of angiographic outcomes. AJNR Am J Neuroradiol 34 : 1987-1992, 2013

4. Chung EJ, Shin YS, Lee CH, Song JH, Park JE : Comparison of clinical and radiologic outcomes among stent-assisted, double-catheter, and balloon-assisted coil embolization of wide neck aneurysms. Acta Neurochir (Wien) 156 : 1289-1295, 2014

5. Consoli A, Vignoli C, Renieri L, Rosi A, Chiarotti I, Nappini S, et al. : Assisted coiling of saccular wide-necked unruptured intracranial aneurysms: stent versus balloon. J Neurointerv Surg 8 : 52-57, 2016

6. Durst $C R$, Starke RM, Gaughen JR Jr, Geraghty S, Kreitel KD, Medel R, et al. : Single-center experience with a dual microcatheter technique for the endovascular treatment of wide-necked aneurysms. J Neurosurg 121 : 1093-1101, 2014

7. Farrell B, Godwin J, Richards S, Warlow C : The United Kingdom transient ischaemic attack (UK-TIA) aspirin trial: final results. J Neurol Neurosurg Psychiatry 54 : 1044-1054, 1991

8. Fernandez Zubillaga A, Guglielmi G, Viñuela F, Duckwiler GR : Endovascular occlusion of intracranial aneurysms with electrically detachable coils: correlation of aneurysm neck size and treatment results. AJNR Am J Neuroradiol 15 : 815-820, 1994

9. Fisher CM, Kistler JP, Davis JM : Relation of cerebral vasospasm to subarachnoid hemorrhage visualized by computerized tomographic scanning. Neurosurgery $6: 1-9,1980$

10. Gory B, Klisch J, Bonafé A, Mounayer C, Beaujeux R, Moret J, et al. : Solitaire $A B$ stent-assisted coiling of wide-necked intracranial aneurysms: mid-term results from the SOLARE study. Neurosurgery 75 : 215-219; discussion 219, 2014

11. Higashida RT, Smith W, Gress D, Urwin R, Dowd CF, Balousek PA, et al. : Intravascular stent and endovascular coil placement for a ruptured fusiform aneurysm of the basilar artery. Case report and review of the literature. J Neurosurg 87 : 944-949, 1997

12. Huang $D Z$, Jiang $B, H$, W, Wang $Y H$, Wang ZG : Risk factors for the

recurrence of an intracranial saccular aneurysm following endovascular treatment. Oncotarget 8 : 33676-33682, 2017

13. Hunt WE, Hess RM : Surgical risk as related to time of intervention in the repair of intracranial aneurysms. J Neurosurg 28 : 14-20, 1968

14. Ishihara H, Ishihara S, Niimi J, Neki H, Kakehi Y, Uemiya N, et al. : Risk factors for coil protrusion into the parent artery and associated thrombo-embolic events following unruptured cerebral aneurysm embolization. Interv Neuroradiol 21 : 178-183, 2015

15. Lee SJ, Cho YD, Kang HS, Kim JE, Han MH : Coil embolization using the self-expandable closed-cell stent for intracranial saccular aneurysm: a single-center experience of 289 consecutive aneurysms. Clin Radiol 68 : 256-263, 2013

16. Lee SY, Chae KS, Rho SJ, Choi HK, Park HS, Ghang CG : Clinical and angiographic outcomes of wide-necked aneurysms treated with the solitaire AB stent. J Cerebrovasc Endovasc Neurosurg 15 : 158-163, 2013

17. Lubicz B, Lefranc F, Bruneau M, Balériaux D, De Witte 0 : Balloonassisted coiling of intracranial aneurysms is not associated with a higher complication rate. Neuroradiology $50:$ 769-776, 2008

18. Medical Advisory Secretariat : Coil embolization for intracranial aneurysms: an evidence-based analysis. Ont Health Technol Assess Ser $6: 1-114,2006$

19. Moret J, Cognard C, Weill A, Castaings L, Rey A : The "remodelling technique" in the treatment of wide neck intracranial aneurysms. angiographic results and clinical follow-up in 56 cases. Interv Neuroradiol 3: 21-35, 1997

20. Murayama Y, Nien YL, Duckwiler G, Gobin YP, Jahan R, Frazee J, et al. : Guglielmi detachable coil embolization of cerebral aneurysms: 11 years' experience. J Neurosurg 98 : 959-966, 2003

21. Nelson PK, Levy DI : Balloon-assisted coil embolization of wide-necked aneurysms of the internal carotid artery: medium-term angiographic and clinical follow-up in 22 patients. AJNR Am J Neuroradiol 22 : 19-26, 2001

22. Raymond J, Guilbert F, Weill A, Georganos SA, Juravsky L, Lambert A, et al. : Long-term angiographic recurrences after selective endovascular treatment of aneurysms with detachable coils. Stroke 34 : 1398-1403, 2003

23. Raymond J, Roy D : Safety and efficacy of endovascular treatment of acutely ruptured aneurysms. Neurosurgery 41 : 1235-1245; discussion 1245-1246, 1997

24. Roy D, Milot G, Raymond J : Endovascular treatment of unruptured aneurysms. Stroke 32 : 1998-2004, 2001

25. Shapiro M, Becske T, Sahlein D, Babb J, Nelson PK : Stent-supported aneurysm coiling: a literature survey of treatment and follow-up. AJNR Am J Neuroradiol 33 : 159-163, 2012

26. Sluzewski M, van Rooij WJ, Beute GN, Nijssen PC : Balloon-assisted coil embolization of intracranial aneurysms: incidence, complications, and angiography results. J Neurosurg 105 : 396-399, 2006

27. Song JH, Chang IB, Ahn JH, Kim JH, Oh JK, Cho BM : Angiographic results of wide-necked intracranial aneurysms treated with coil embolization : a single center experience. J Korean Neurosurg Soc 57 : 250- 
257, 2015

28. Starke RM, Durst CR, Evans A, Ding D, Raper DM, Jensen ME, et al. : Endovascular treatment of unruptured wide-necked intracranial aneurysms: comparison of dual microcatheter technique and stent-assisted coil embolization. J Neurointerv Surg 7 : 256-261, 2015
29. Taylor RA, Callison RC, Martin CO, Hayakawa M, Chaloupka JC : Acutely ruptured intracranial saccular aneurysms treated with stent assisted coiling: complications and outcomes in 42 consecutive patients. J Neurointerv Surg 2 : 23-30, 2010 